\title{
The contribution for occupational health protection*
}

\author{
MARIJANA BAĐUN Institute of Public Finance
}

There has been a lot of discussion in the public about the compulsory pension insurance and compulsory basic and supplementary health insurance contributions, while the contribution for compulsory health insurance against accidents at work and occupational diseases has been neglected. We are talking about a contribution for occupational health protection, calculated at a rate of $0.5 \%$ of a monthly base. Despite the low rate, the revenues collected are considerable. This paper analyses how the Croatian Health Insurance Fund (CHIF) spends the funds collected from the contribution for occupational health protection.

\section{INTRODUCTION}

A large number of employed persons sustain workplace injuries or get ill due to harmful workplace effects. The ensuing material and nonmaterial consequences are very serious, and are borne by employees, employers and government (European Commission, 20II). From the employee's perspective, nonmaterial consequences include pain, suffering, erosion of self-confidence, lifestyle changes, etc., whereas material effects can be: loss of income, potentially impaired ability to work and medical costs. Employers may suffer from reputation damage or changes in working relationships within the company; the material effects comprise productivity losses, increases in insurance premiums, replacement costs, compensation of damages and legal costs. From the perspective of the state, nonmaterial effects include the loss of human resources, accompanied by growing costs of medical treatment, rehabilitation, sick leave and early retirement, or the costs of relevant social benefits.

Although it is difficult to estimate the total costs of accidents at work and occupational diseases, this is highly beneficial for better understanding the importance of occupational health protection and safety at work. There are many studies on this subject for highly developed countries (see EU-OSHA, 2OI4). However, this Newsletter focuses on only a small fragment of total economic costs, i.e. the CHIF's expenditures for accidents at work and occupational diseases, financed from the contribution for occupational health protection.

\footnotetext{
* This survey is part of the project „Parity Fund to Strengthen Social Dialogue in the Construction Sector”. The project is managed by the Croatian Employers' Association (CEA) and co-financed by the European Social Fund. The views expressed in this article are those of the author and do not in any way represent the position or official views of the CEA.
} 
Eurostat publishes data on health and safety at work for all the EU Member States, additionally including Iceland, Norway and Switzerland. The sources of data used are the ESAW (European Statistics on Accidents at Work) database and the Labour Force Survey. Data are classified by characteristics of injured workers (age, gender and occupation), economic activity and size of employer, type of injury and days of absence from work. The latest available data relate to 2013, when a total of 3.Im accidents were recorded. Included were only accidents that resulted in at least three calendar days of absence from work. The highest incidence of accidents was recorded in Germany (27\%), followed by France (18\%), Spain (I2\%), Italy (II\%) and Great Britain (8\%). At the bottom of the scale were Cyprus, Latvia, Bulgaria and Malta, while Croatia ranked IIth on the number of accidents, if countries are sorted in ascending order. All Member States (except Sweden) reported lower incidence rates than in 2008, which was due to lower employment caused by the economic crisis. Obviously, the incidence of accidents depends on the size of economy, or the number of persons employed. Therefore, it may be more useful to look at the incidence of accidents at work per IOo,ooo persons employed.

\section{Graph I}

Non-fatal accidents at work per Ioo,ooo employed persons in the EU, 2013

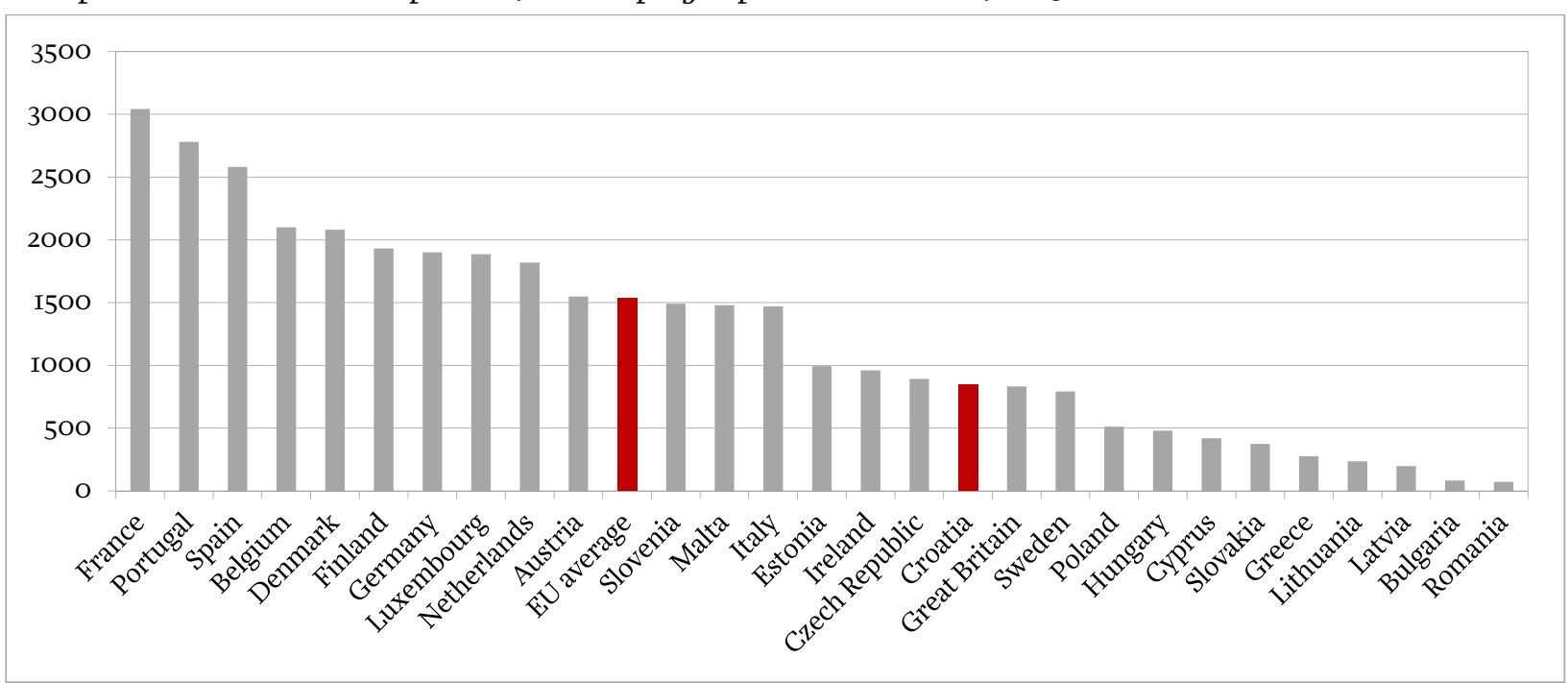

Source: Eurostat (2016).

The 2013 EU average was I,533 accidents (excluding fatal accidents) per 10o,ooo persons employed (graph I). France led with the largest number of accidents at work per Ioo,ooo persons employed, followed by Portugal and Span. The lowest incidence rates were recorded in Romania, Bulgaria and Latvia. Croatia performed better than the EU average, with 843 accidents per Ioo,ooo persons employed. Worth noting are some statistical problems concerning accidents at work, such as: (I) under-reporting in some Member States (particularly Bulgaria, Latvia, Lithuania and Romania, according to Eurostat); (2) questionable accuracy of data on the number of employed persons by activity (which influences the incidence rate of accidents); and (3) differences across countries in the definition of persons subject to reporting obligation. The problem under (I) arises from either employers' ignorance or their fear of the financial damage for the company due to higher needs for investment in safety at work.

In 2013, fatal accidents at work in the EU totalled 3,674. In terms of the number of such accidents per IOO,Ooo persons employed, leaders were Romania, Lithuania and Portugal, while the Netherlands, Greece and Sweden ranked the lowest on the scale (graph 2). Croatia reported 2.I fatal accidents at work per IOo,ooo persons employed (the EU average was I.8). It is noticeable that the country rankings in graph 2 differ from those in graph I, i.e. on average, the more developed the EU Member State the lower the number of fatal accidents. This points to better safety at work in these countries, but also the fact that 
severe accidents and fatal accidents are almost always reported, which explains the more accurate statistics. In Croatia, fatal accidents at work are reported to the CHIF. However, the sources of problems are the "black economy" and employers' fear of potential claims for damages.

\section{Graph 2}

Fatal accidents at work per IOO,OOO persons employed in the EU, 2013

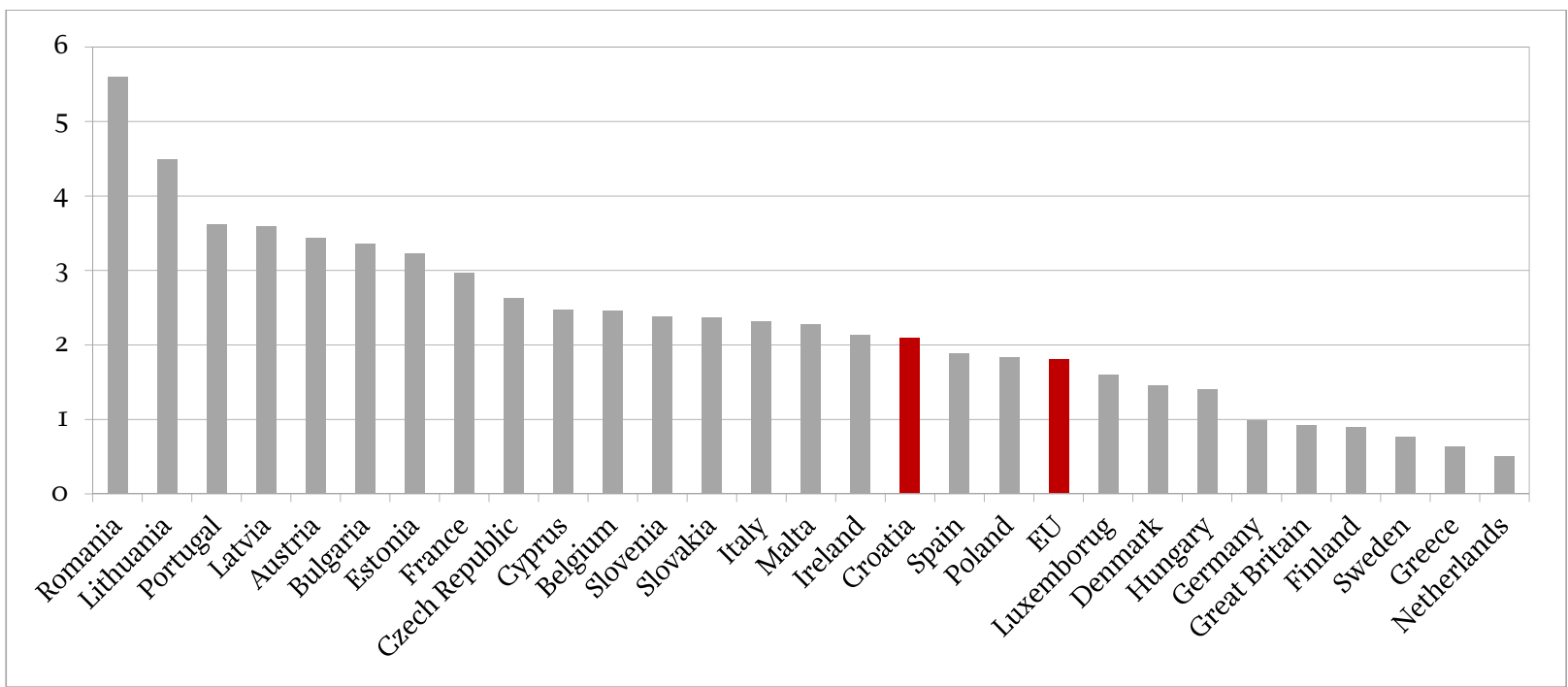

Source: Eurostat (2016).

Using the Labour Force Survey, Eurostat also publishes data on exposure to risk factors that can adversely affect physical and mental health. Looking at all economic activities and the age group of 15 to 64 years, the share of surveyed persons with exposure to risk factors that could adversely affect physical health in Croatia stood at $48 \%$ in 2013, compared with an EU average of $51 \%$. When it comes to adverse effects on mental health, Croatia's share was $20 \%$ (28\% in the EU).

\section{Graph 3}

Accidents at work (in thousands) and incidence rate of accidents at work per 100,00o active insured persons in Croatia

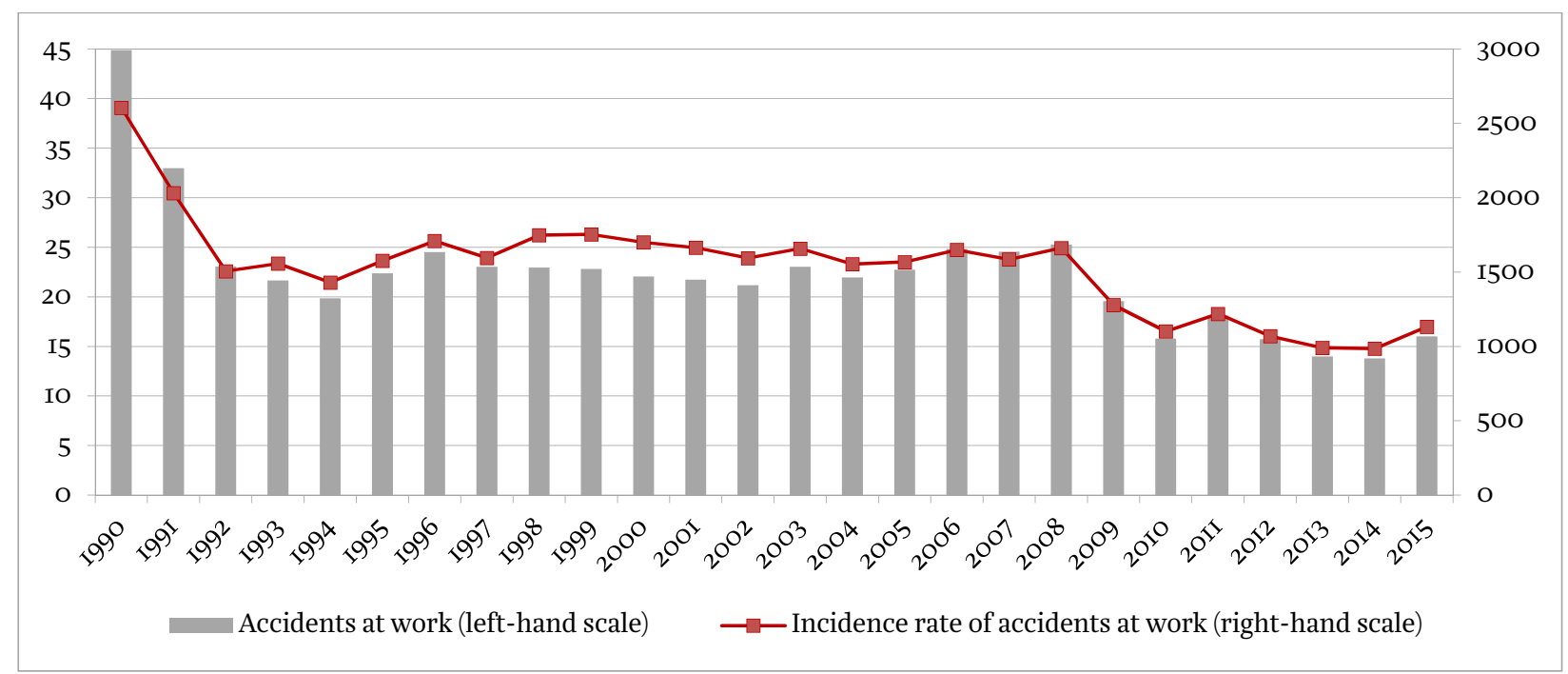

Sources: CIPH, for data from 2005 onwards, and MINELE (2008) for the previous period data which are also based on the CIPH data.

Graph 3 shows only data for Croatia in the period 1990-2015. The data were provided by the Croatian Institute of Public Health (CIPH), because they represented the longest continuous time series. The CIPH keeps a Register of Persons with Occupational Diseases and Workplace Injuries. The sharpest fall in the number of accidents was recorded from 1990 to 1992, and again from 2008 to 20I4, as a result of an 
economic downturn. The largest number of accidents $(44,900)$ was reported in 1990 and the smallest in 2014 (13,785). In 2015, there were I6,OI5 accidents at works. The highest-risk activities in terms of the incidence of accidents at the workplace itself (excluding accidents on the way to and from work) per IOO,OOO persons employed in 2015 included: transportation and storage (I,95I accidents), water supply, sewerage, waste management and environmental rehabilitation (I,405 accidents), art, entertainment and recreation $(\mathrm{I}, 373)$ and manufacturing $(\mathrm{I}, 267)$. The largest number of fatal accidents has been recorded for many years in construction, and the largest total number of accidents was seen in manufacturing.

Table I

Differences in the numbers of accidents at work in the national statistics

\begin{tabular}{|c|c|c|c|c|c|}
\hline \multicolumn{3}{|c|}{ Accidents at work } & \multicolumn{3}{|c|}{ Fatal accidents at work } \\
\hline & CIPH & CBS & GIHPSW & GIPH & GIHPSW \\
\hline 2007 & 24,550 & 73,384 & - & 77 & - \\
\hline 2008 & 25,285 & - & - & 80 & - \\
\hline 2009 & 19,566 & - & I6,II8 & 32 & - \\
\hline $2 \mathrm{OIO}$ & I5,79I & - & 13,588 & 38 & 19 \\
\hline $2 \mathrm{OII}$ & I8,II6 & 15,903 & I3,8I7 & 46 & 19 \\
\hline 2012 & $\mathrm{I} 5,74 \mathrm{I}$ & $\mathrm{I} 4,45 \mathrm{I}$ & I4,076 & 23 & I4 \\
\hline 2013 & 13,988 & I3,6I3 & 13,796 & 27 & 17 \\
\hline 2014 & $\mathrm{I} 3,785$ & I2,313 & 13,929 & 36 & 8 \\
\hline
\end{tabular}

Sources: CIPH, CBS and CIHPSW.

As shown in table I, the Croatian Bureau of Statistics (CBS), Croatian Institute for Health Protection and Safety at Work (CIHPSW) and CIPH publish different accidents at work data, although they all cite the same source, i.e. CHIF. The CBS notes that, as of I January 20II, after the Croatian Institute for Occupational Health and Safety Health Insurance had merged with the CHIF, „the 2OII data on days of absence from work due to accidents at work and occupational diseases can be shown again”. More specifically, the CBS yearbooks do not contain data on the numbers of accidents at work for 2008, 2009 and 20IO. On the other hand, the data on the number of accidents at work, e.g. for 2007 (73,384), comes from the „monthly reports of primary health care physicians, who are the first to contact the injured”, while the CIPH indicates a figure of 24,550 accidents at work for the same year. The CIHPSW data have been available since 2009, when the Croatian Institute of Occupational Health (established in 1996) became the CIHPSW. The number of accidents at work presented by the CIPH for the period 2OII-I3 was larger than the numbers reported by the other two sources. In 20I4, however the figure presented by the CIHPSW was larger. The differences are likely due to the fact that accidents at work can be reported up to three years from their occurrence, and there are also inaccuracies in the use of terms, for example: (I) the number of accidents at work reported in a given year (which may have occurred, e.g. two years ago); (2) the number of accidents at work reported and occurred in a given year; and (3) the number of accidents at work recognized by the CHIF for a given year. In any case, in order to avoid such discrepancies in the national statistics, a unified methodology should be used. The ESAW methodology takes into account accidents at work reported in the observed year, but excluding accidents on the way to and from work.

Discrepancies in data are even more striking when comparing the fatal accidents figures provided by the CIPH and the CIHPSW. For example in 2OIO, the former source reported 38 fatal accidents and the latter 19. Moreover, in its analyses for 2013-I4, the CIHPSW only published figures on the fatal accidents occurred at the workplace, without indicating their total number (i.e. excluding accidents on the way to and from work). The CIHPSW noted that the data on fatal accidents only showed the number of accidents that led to the death of an injured person up to the moment of drawing a report on the accident at work. Under the ESAW methodology, a fatal accident means an accident which leads to the death of a victim within one year of the accident. In the case of fatal accidents, the CIPH cites as sources not only the CHIF, but also the Labour Inspectorate and the Statistical Report on Death. 
The Government plans to merge the CIHPSW with CIPH. To this end, the Ministry of Health is required to prepare a proposal for the necessary legal changes no later than 30 September 2016 (Government of the RC, 20I6). The CIHPSW has 49 employees and was given HRK 7.3m from the central budget (CIHPSW, 20I6). In 20I4, an Institute for Safety at Work Improvement was established, with I6 employees and 5 members of the Governing Council. According to the revised 2015 Budget Plan, the Institute's expenditures are HRK 3.5m (Ministry of Finance, 2015).

The CIPH data on the number of reported occupational diseases per year do not clearly show any downward or upward trend. The largest number of reported occupational diseases per 100,000 active insured persons was recorded in 1995 (26.2), and the smallest in 1999 (4.54). Data for 2015 are not available; in 2014 there were 168 reported cases of occupational diseases with an incidence rate of 12 per Ioo,0oo persons employed. Sixty-four percent of reported occupational diseases related to asbestosis. The highest incidence of occupational disease was recorded in manufacturing (71\%), health protection and social welfare $(8 \%)$ and agriculture, forestry and fisheries $(7 \%)$. The most frequently reported in 2014 were respiratory diseases caused by asbestos exposure, overuse syndromes caused by repetitive trauma, infectious or parasitic diseases caused by performing activities where there is evidence of an increased risk of infection, diseases caused by vibrations transmitted to the hand, skin diseases caused by substances with scientifically confirmed allergic or irritating effects and noise-induced hearing loss or deafness.

\section{HEALTH INSURANCE RIGHTS IN THE GASES OF WORK-RELATED AGGIDENTS AND DISEASES}

Compulsory health insurance rights, including rights in the cases of work-related accidents and diseases comprise a right to health protection and a right to financial compensation. According to Article I8 of the Compulsory Health Insurance Act (CHIA), the right to health protection includes:

- primary health protection;

- specialist and consultative health protection;

- hospital health protection;

- a right to drugs determined in the CHIF's basic and supplementary drug lists;

- dental aids determined in the CHIF's basic and supplementary dental aids lists;

- orthopaedic and other aids determined in the CHIF's basic and supplementary list of orthopaedic and other aids;

- health protection in other Member States and third countries.

In the case of accidents at work and occupational diseases, the CHIF covers the full costs of medical services for the entire treatment as a consequence of a recognized accident at work or an occupational disease.

The compulsory health insurance rights in the cases of work-related accidents and diseases also include specific health protection measures for employees, regulated by the Health Protection Act (Article 7I) and special laws and regulations, primarily preventive medical examinations of employees ${ }^{\mathrm{I}}$ which include preliminary and periodical examinations, medical checkups and diagnostic procedures for the purpose of occupational disease identification, as well as monitoring and analysing morbidity caused by accidents at work and occupational diseases. The CHIF bears the costs of: medical examinations, the training of employees on acute effects of hazardous exposure at work, training of employees on work ability maintenance, including counselling on health and safety at work and the counselling of chronically diseased persons. Along with the said training measures, within a specific health protection programme,

' See „Regulations on Activities Which a Worker Can Perform Only Subject to Preliminary and Regular Assessment of Medical Fitness" (OG, 70/IO) and the Decision on the Grounds for Concluding a Contract on the Implementation of Specific Health Protection (OG, 47/I4, I57/I4, I39/I5 and 28/I6). 
the CHIF also organises visits to workplaces for the assessment of the medical fitness of employees and specific job requirements.

According to Article 37 of the CHIA, the right to financial compensation for work-related injuries and occupational diseases includes the following:

- salary compensation during temporary inability to work (sick leave);

- reimbursement of transportation costs related to the use of health care services;

- reimbursement of funeral costs in the case of an insured person's death, directly caused by a recognised accident at work or an occupational disease.

In the case of a recognised accident at work or an occupational disease, the compensation is calculated and paid by the employer from the first day of inability to work, and the CHIF is obliged to refund the compensation to the employer within 45 days from the day of receipt of the refund request (Article 4I). The salary compensation amounts to IOo\% of the salary compensation base and the maximum amount is not limited. Moreover, in the case of an accident at work or occupational disease, the payment of salary compensation is not subject to the minimum service period prescribed by Article 56 of the CHIA. The salary compensation provided by the CHIF at a rate of IOo\% of the base can be continuously paid for a maximum of I8 months for the same disease diagnosis (Article 52). After the expiry of that period, an insured person is entitled to salary compensation at a rate of $50 \%$ of the last salary compensation paid, as long as there is a medical indication for temporary inability to work. After I2 months of continuous sick leave, the chosen family doctor refers the insured person to a Single Body of Expertise for the assessment of his/her ability to work.

\section{THE GONTRIBUTION FOR OCGUPATIONAL HEALTH PROTEGTION}

According to the Contribution Act, accidents at work and occupational diseases are covered by: (a) a contribution for occupational health protection (o.5\%); and (b) a special contribution for occupational health protection (0.5\%), relating to persons insured under certain circumstances (e.g. unemployed persons during vocational training or rehabilitation, pupils and graduate-level students during practical training and internship with employers and during professional trips, pupils and regular students during their work through intermediaries, etc. (see Article I6 of the CHIA). Like the health insurance contribution, the contribution for occupational health protection is calculated from a monthly base. For a person insured on the basis of employment, the contribution payer is the employer or another person paying the salary to the insured person in lieu of the employer. The monthly calculation base is the gross salary or earnings from employment subject to personal income tax, as well as other receipts from employment subject to personal income tax (Articles 2I and 22 of the Contribution Act). The contribution is also payable by selfemployed persons (Article 80) and other categories of insured persons defined in the Contribution Act.

The manner of paying the contribution for occupational health protection is governed by the Ministry of Finance's Order on the Manner of Payment of Budget Revenues, Compulsory Contributions and Revenues for the Financing of Other Public Needs. As of I January 2015, the CHIF came out of the state treasury system and became an extra-budgetary user of the state budget, whose Financial Plan is subject to Parliament's approval. The revenues of the CHIF are excluded from the national budget revenues and, together with expenditures financed therefrom, they constitute part of the CHIF’s Financial Plan.

\section{I REVENUES FROM CONTRIBUTIONS FOR OCCUPATIONAL HEALTH PROTECTION}

Revenues from contributions for occupational health protection totalled around HRK 579.6 in 2015 (graph 4) and were the highest for the observed period (2OII-I5). Now, what are the collected contribution 
revenues spent on? The main expenditure items, which will be discussed individually, include: (I) salary compensation for temporary inability to work caused by a recognized accident at work or an occupational disease; and (2) CHIF's expenses for health protection in the cases of work-related injuries or diseases. The salaries of the Safety at Work Service employees and all employees engaged in occupational health protection are paid from the total wage bill of the CHIF. Also included are other administrative expenditures, such as material, financial and other expenditures, expenditures for the acquisition of nonfinancial assets, etc. The Safety at Work Service has four employees. There are also Departments of Occupational Safety and Health, established within the regional offices, with a total of I6 employees. In all other organisational units (regional services, local offices and locations) all tasks are performed by all employees. At the end of 20I5, the CHIF had around 2,300 employees.

\section{Graph 4}

Revenues from contributions for occupational health protection (in million HRK)

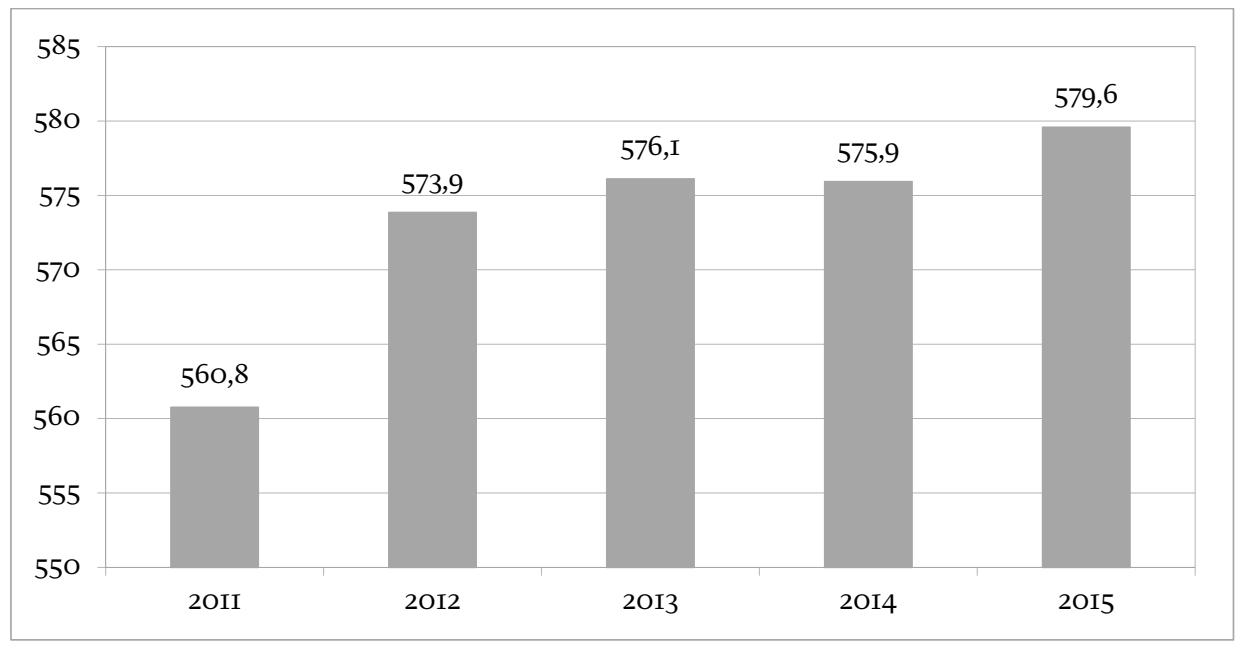

Source: CHIF, Business Reports of the CHIF.

\subsection{SALARY COMPENSATION FOR TEMPORARY INABILITY TO WORK GAUSED BY WORK-RELATED ACCIDENTS AND DISEASES}

Graph 5 shows data on salary compensation for temporary inability to work caused by a recognised accident at work or an occupational disease. It should be reminded that the salary compensation is paid in full at the expense of the CHIF, starting from the first day of sick leave. In 20I5, salary compensation for accidents at work and occupational diseases paid by the CHIF totalled around HRK I68.4 (the amount planned was HRK 205m), i.e. around $7.5 \%$ of overall compensation paid by the Fund. The amount of salary compensation for work inability caused by accidents at work and occupational diseases declined from $2 \mathrm{OII}$ to 20I4, but resumed growth in 2015, by as little as $\mathrm{I.7} \%$ from 20I4, when salary compensation totalled HRK $165.6 \mathrm{~m}$. It is worth noting that this expenditure item also includes health care-related travel expenses, transportation costs of deceased persons and reimbursement for drugs. However, the salary compensation accounts for as much as $99 \%$ of the said amount. 


\section{Graph 5}

Salary compensation for temporary inability to work caused by a recognised accident at work or an occupational disease (in million HRK)

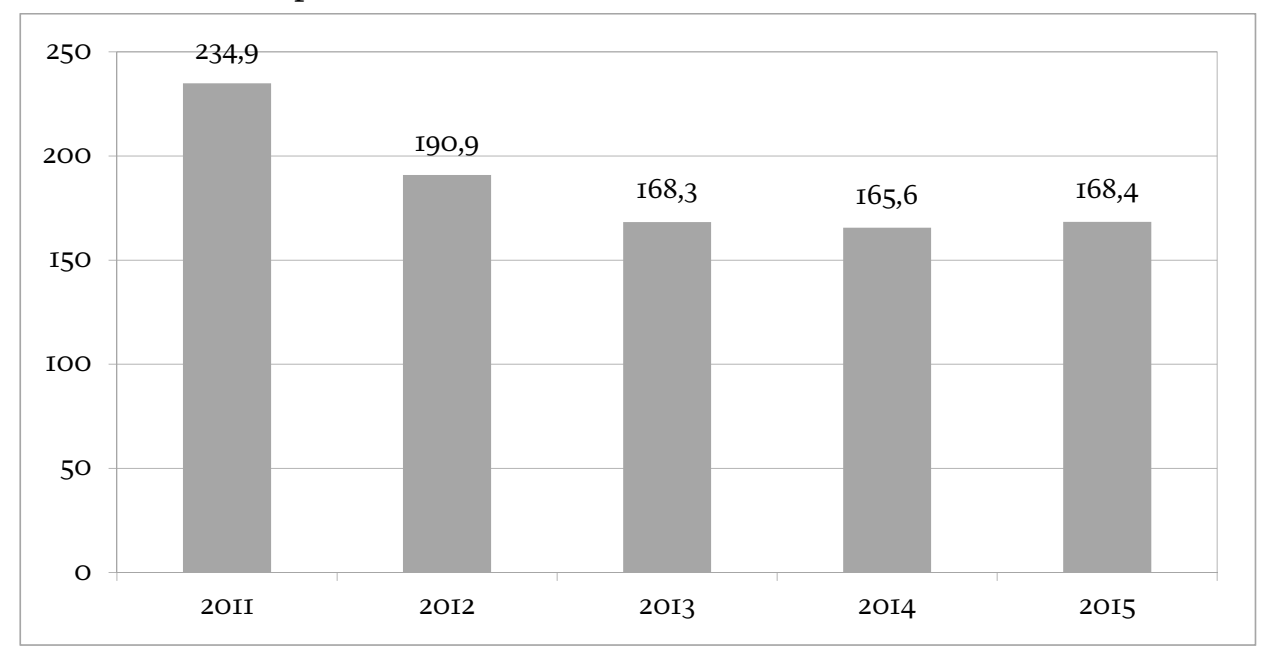

Source: CHIF, Business Reports of the CHIF.

Table 2 shows data on days of temporary inability to work, i.e. absence from work, due to accidents at work or occupational diseases. Days of temporary work inability due to accidents at work or occupational diseases totalled 859,747 in 2015; the average number of absent employees per day was 2,747 and the average duration of temporary inability to work was 68 days. For comparison, the total absence from work data show that there were 13.9m days of absence from work, 44.390 absent employees per day and the average duration of temporary inability to work was 16.5 days. It follows that sick leave due to accidents at work and occupational diseases lasts longer on average. The rate of temporary inability to work is obtained by dividing the number of sick persons by the number of the active insured. In 2015, the inability rate for accidents at work and occupational diseases was 0.19\% and the total rate 3.03\%.

Table 2

Absence from work due to temporary inability to work caused by accidents at work or occupational diseases

\begin{tabular}{|c|c|c|c|c|}
\hline & Days & $\begin{array}{c}\text { Daily average of } \\
\text { absent employees }\end{array}$ & $\begin{array}{c}\text { Average days of } \\
\text { absence }\end{array}$ & Rate (\%) \\
\hline $20 I I$ & 986,520 & 3,152 & 6I.44 & $0.2 \mathrm{I}$ \\
\hline 2012 & 897,920 & 2,869 & 62.14 & 0.20 \\
\hline 2013 & 806,265 & 2,576 & 59.23 & 0.18 \\
\hline 2014 & 797,408 & 2,548 & 64.76 & 0.18 \\
\hline 2015 & 859,747 & 2,747 & 67.94 & 0.19 \\
\hline
\end{tabular}

Source: CHIF, Business Reports of the CHIF.

\subsection{EXPENDITURES FOR HEALTH PROTEGTION IN THE GASES OF WORK-RELATED ACGIDENTS AND DISEASES}

The CHIF's expenditures for health protection in the cases of work-related accidents and diseases stood at around HRK $78.6 \mathrm{~m}$ in 2015 (the amount planned was HRK $105.5 \mathrm{~m}$ ) and around HRK 74,8m a year before (graph 6). Part of the former amount was spent for the settlement of liabilities from the previous period, whereas part of the current period's liabilities remained unsettled. The expenditures decreased from $201 \mathrm{II}$ to 20I4, but rose again afterwards; they included the costs of health protection and pharmacy services, expert opinions given by the CIHPSW, hospital costs, the costs of specialist and consultative health protection services, orthopaedic aids and pharmaceutical products, health care costs, the costs of services of special rehabilitation hospitals, etc. Expenditures for health protection in the cases of work-related accidents and diseases also include outlays on specific health protection, primarily preventive medical 
examinations at the expense of the CHIF, the cost of which is around HRK 45m annually (200,000 examinations at the price of HRK 225 per examination). It should be noted that the CHIF also pays compensation of damages to persons suffering from asbestosis, although these costs are not included in the health protection expenditures (the amount paid is HRK 20m, according to amendments to the 2015 financial plan). The CHIF' business reports do not provide data on expenditures for health protection in the cases of work-related accidents and diseases by expenditure items.

\section{Graph 6}

CHIF expenditures for health protection in the cases of work-related accidents and diseases (in million HRK)

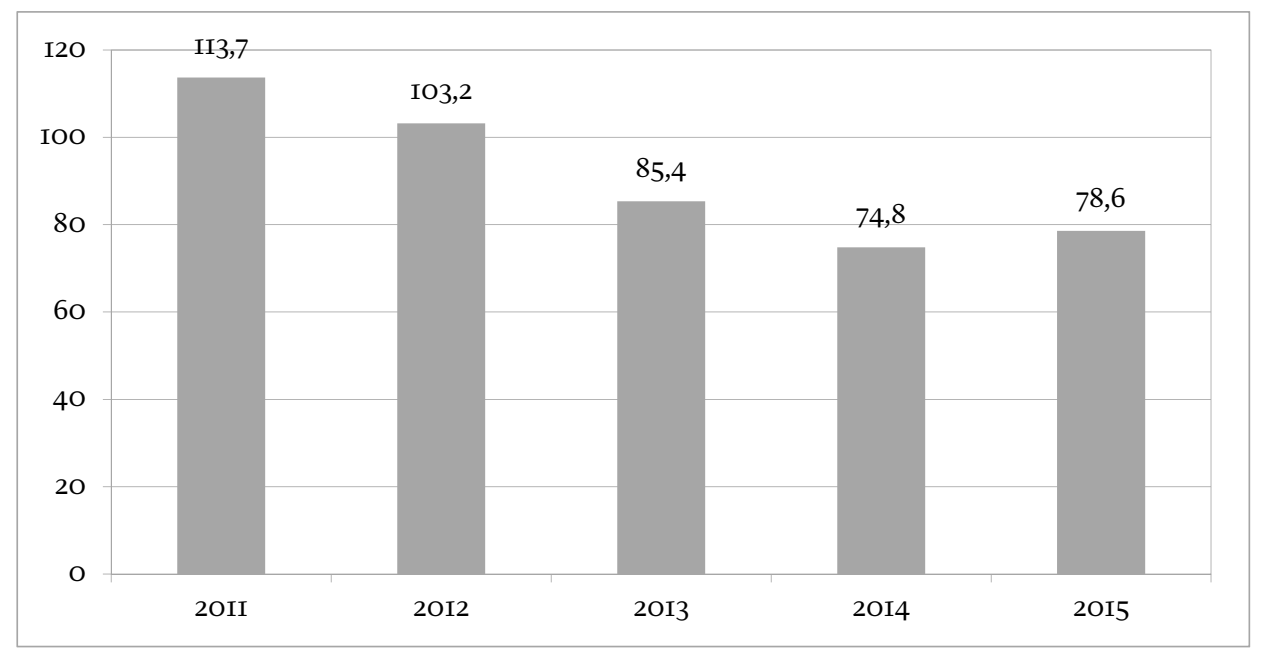

Source: CHIF, Business Reports of the CHIF.

\subsection{DIFFERENCE BETWEEN REVENUES FROM AND EXPENDITURES FOR OCGUPATIONAL HEALTH PROTEGTION}

After the 2012 audit of the CHIF relating to the contribution for occupational health protection, carried out by the State Audit Office, the following conclusion was reached: „Given the obligation to pay the contributions and purposes for spending the collected contribution revenues, regulated by the Contribution Act and Compulsory Insurance Act and determined in the CHIF's financial plan and state budget, and given that the contributions paid for $2 \mathrm{OII}$ and $2 \mathrm{OI} 2$ considerably exceeded the expenditures financed therefrom, the State Audit Office suggests, in agreement with the Ministry of Health, reviewing the rate of insurance contribution for accidents at work and occupational diseases. It is ordered that expenditures be executed in accordance with the purposes and activities laid down in the Budget Act” (SAO, 2OI3, p. 20).

Graph 7 shows the gap between the CHIF's revenues from and expenditures for occupational health protection. The expenditures include salary compensation for temporary work inability caused by recognised accidents at work or occupational diseases and the CHIF's expenditures for health protection in the cases of work-related accidents and diseases. The graph confirms the warning from the State Audit Office, namely that the contribution revenues exceed the expenditures financed therefrom. In 20I5, around $14 \%$ of collected contributions (HRK $78.6 \mathrm{~m}$ ) was spent on health protection in the cases of workrelated accidents and diseases, around 29\% (HRK I68.4m) on salary compensation for temporary work inability/sick leave, and the remaining $57 \%$ HRK $332.6 \mathrm{~m}$ ) of collected revenues were spent inappropriately. The revenue-expenditure gap has soared over the years: from 2011 to 2015 revenues picked up $3 \%$ while expenditures dropped by $29 \%$. 


\section{Graph 7}

Gap between CHIF revenues from and expenditures for occupational health protection (in million HRK)

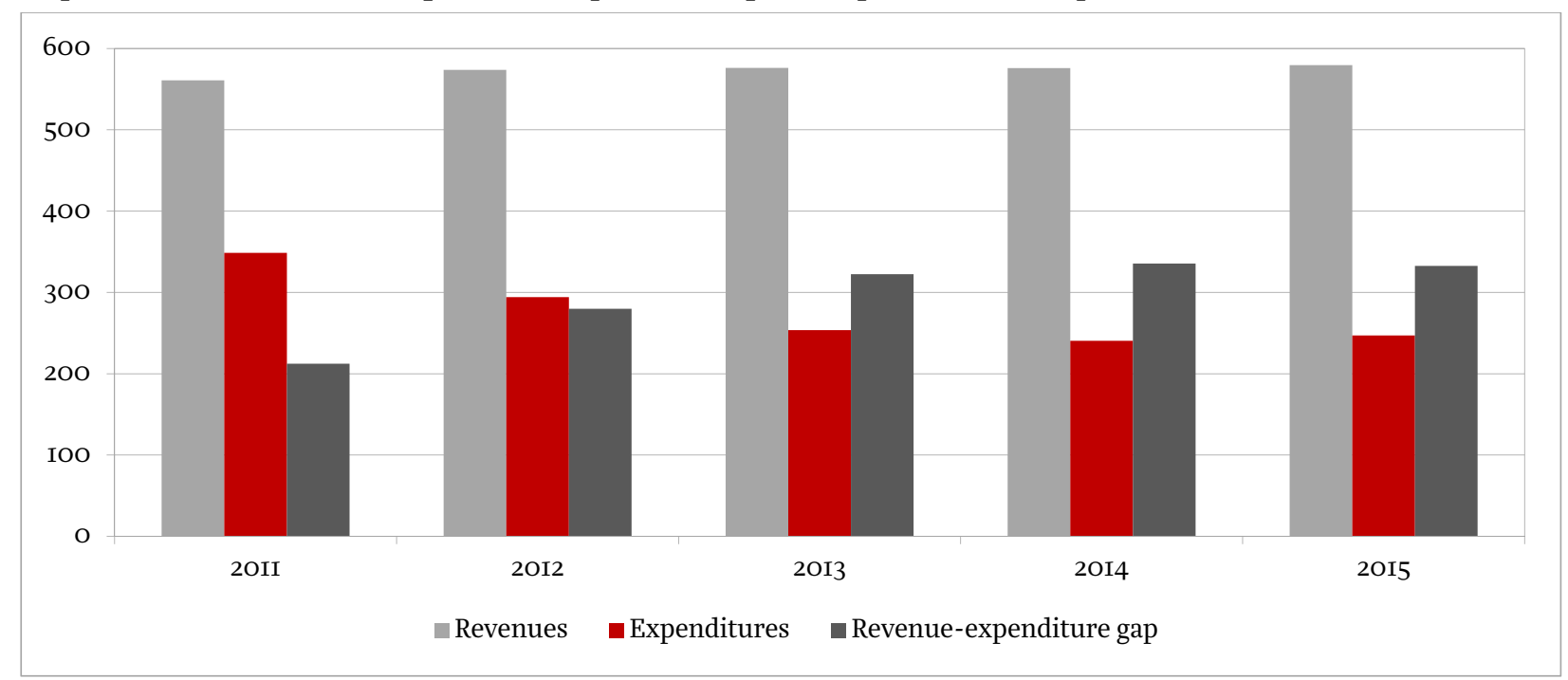

Source: CHIF (2OII-2OI5).

However, these data should be taken with some reservations. As already mentioned, the amount of administrative expenditures for occupational health protection is unknown, because these costs are included in total administrative expenditures. Moreover, according to the information provided by the CHIF upon an Access to Information Request, expenses related to work injuries and occupational diseases, incurred from the occurrence of the relevant event to the recognition of the right arising from a reported accident or disease (and this is when the expenses reach their peak), are not recorded as occupational health protection expenses, but are included in the general health protection expenditures within the basic health insurance. This is also how they are presented in the annual reports of the CHIF which currently has inadequate technical capacity to mark the occupational health protection expenses separately. In 20I4, the average period from the receipt of a report to the recognition of the right was 37 days. Some reports of work injuries are simple and can be recognised almost immediately, by certifying the report, whereas others are more complex, e.g. when there are inconsistencies in the statements of injured person, witnesses and the employer, as well as in the police report, or when legal proceedings or Labour Inspectorate investigation are pending, etc. Reports of occupational diseases include special medical diagnostic and evaluation procedures, harmonisation of medical opinions concerning the diagnoses, etc. Also, according to the CHIA, accidents at work and occupational diseases can be reported even three years after their occurrence and all costs incurred during that period are borne by the compulsory (basic) health insurance.

Although the CHIF depends on some external factors when processing the reports of work-related accidents and diseases, it is still unclear why it does not have a separate business fund for compulsory health insurance in the cases of work-related accidents and diseases, as provided by Article 83 of the CHIA. A business fund for occupational health protection is also envisaged in the Statute of the CHIF (Article 6I): „The Fund keeps its business books in the way that it monitors receipts/revenues by source, for the: following: business fund for compulsory health insurance, business fund for compulsory health insurance in the cases of work-related accidents and diseases, business fund for supplementary health insurance and business fund for additional health insurance implemented by the Fund, as well as the programmes and activities determined in the state budget for each budget year." Currently, there are only special funds for compulsory health insurance (which includes occupational health protection) and supplementary health insurance. Formerly, there was also a Croatian Institute for Occupational Health and Safety Health Insurance (CIOHSHI), but it merged with the CHIF on I January 2011. 
Furthermore, the CHIF's 20I5 Financial Plan for Health Insurance and Projections for 20I6-I7 suggest that revenues from contributions for the compulsory occupational health protection are not shown separately, but in aggregate terms, as health insurance contribution revenues. By contrast, salary compensation for temporary inability to work caused by a recognized accident at work or an occupational disease, as well as expenditures for occupational health protection are shown separately under 'expenditures'.

\section{Conclusions}

At first glance, it appears that the revenues from occupational health protection contributions payable by employers considerably exceed the relevant expenditures. In 2015, the revenue-expenditure gap was HRK $332.6 \mathrm{~m}$. However, given inaccuracies in the data on health protection expenditures in the cases of work-related accidents and diseases (because the expenditures are covered from compulsory health insurance until the recognition of the right), further specific analyses are necessary to establish the actual amount of the CHIF's occupational health protection expenditures. Therefore, the CHIF should capture the total costs of health protection at the time of their occurrence.

The CHIF should urgently set up a separate business fund for health insurance in the cases of workrelated accidents and diseases (which should have already been in place, according to the CHIA and the Fund's Statute). The following measures should be taken:

- Reported accidents at work and occupational diseases should be recognised in urgent procedures (as little as $15 \%$ of reported accidents at work in 2015 remained unrecognised);

- The health protection costs should be charged to the Occupational Health Protection Fund as soon as a person reports that an accident at work or occupational disease has occurred;

- A methodology should be developed for booking/debiting material costs, e.g. as a percent of total costs;

- Following the above measures, the contribution rate for occupational health protection should be reviewed;

- The CHIF's IT-system should be upgraded to enable monitoring of expenditures by activities and by all purposes;

- Data on the number of work-related accidents in the national statistics should be harmonised.

The Government intends to merge the CIHPSW with the Croatian Institute of Public Health, but it should also carry out an evaluation of operations of the Institute for Improving Safety at Work and other relevant institutions (such as the National Council for Occupational Safety and Health, relevant departments of the CHIF and Ministry of Labour and Pension System, Institute for Medical Research and Occupational Health and Labour Inspectorate), in order to identify potential competence overlaps and system deficiencies, and find new activity-specific solutions towards more effective prevention of work-related accidents. In the long run, this could also help reduce government expenditures for occupational health and safety promotion.

\section{REFERENGES}

Act on the List of Occupational Diseases (Zakon o listi profesionalnih bolesti), OG I62/98, I07/o7.

CBS, 20IO-2015. Statistical Yearbooks. Zagreb: Croatian Bureau of Statistics.

CHIF, 2OII-2OI5. Business Report of the Croatian Health Insurance Fund (in Croatian). Zagreb: Croatian Health Insurance Fund. 
CHIF, 20I3. Statute of the Croatian Health Insurance Fund, unofficial consolidated text (in Croatian). Zagreb: Croatian Health Insurance Fund.

CIHPSW, 2009-20I4. An Analysis of Work-related Injuries (in Croatian)._Zagreb: Croatian Institute for Health Protection and Safety at Work.

CIHPSW, 2016. The 2015 Financial Report (in Croatian)._Zagreb: Croatian Institute for Health Protection and Safety at Work.

CIPH, 2005-20I4. Croatian Health Service Yearbook (in Croatian). Zagreb: Croatian Institute for Public Health.

Compulsory Health Insurance Act (Zakon o obveznom zdravstvenom osiguranju), OG 80/13, I37/13.

Contribution Act (Zakon o doprinosima), OG 84/o8, I52/O8, 94/o9, I8/II, 22/I2, I44/I2, I48/I3, 4I/I4, I43/I4.

EU-OSHA, 2OI4. Estimating the cost of accidents and ill-health at work. European Agency for Safety and Health at Work.

European Commisssion, 20II. Socio-economic costs of accidents at work and work-related ill health.

Eurostat, 20I6. Health and Safety at Work.

Government of the RC, 20I6. Nacionalni program reformi 2016. Vlada Republike Hrvatske.

Health Protection Act (Zakon o zdravstvenoj zaštiti), OG I5O/O8, 7I/IO, I39/IO, 22/II, 84/II, I54/II, I2/I2, 35/I2, 70/I2, I44/I2, 82/I3, I59/I3, 22/I4, I54/I4.

MINELE, 2008. National Programme of Health Protection and Safety at Work, 2009-I3 (in Croatian). Zagreb: Ministry of Economy, Labour and Entrepreneurship.

Ministry of Finance, 2015. Amendments to the 2015 State Budget of the Republic of Croatia (Izmjene i dopune Državnog proračuna Republike Hrvatske za 2015. godinu), OG IO3/I5.

Order on the Manner of Payment of Budget Revenues, Compulsory Contributions and Revenues for the Financing of Other Public Needs (Naredba o načinu uplaćivanja prihoda proračuna, obveznih doprinosa te prihoda za financiranje drugih javnih potreba u 2OI5. godini), OG IO3/I5.

SAO, 2013. Audit Report - Croatian Health Insurance Fund. Zagreb: State Audit Office.

The Croatian Health Insurance Fund's 2015 Financial Plan and Projections for 2016-I7 (Financijski plan Hrvatskog zavoda za zdravstveno osiguranje za 2015. i projekcije plana za 2016. i 20I7. godinu), OG I48/I4, IO3A/I5.

\section{ANNEX}

DI. Definition of 'work-related injury' and 'occupational disease' according to the Compulsory Health Insurance Act

According to Article 66 of the Compulsory Health Insurance Act (CHIA), a work-related injury is considered to be:

- any injury caused by an immediate mechanical, physical or chemical action of short duration, or injury caused by rapid changes in body posture, sudden loads on the body or other changes in the physiological condition of the body, provided there is a causal relationship between such injuries and the performance of tasks or activities which are the basis for the insured person's compulsory health insurance, as well as an injury sustained by the insured person during mandatory fitness training necessary for maintaining his/her adequate physical condition for the performance of relevant activities;

- any disease caused directly and exclusively by an accident or act of God during the work, or during, or related to, the performance of an activity which is the basis for the insured person's compulsory health insurance; 
- any injury sustained in the manner described in the first subparagraph, if it occurred on the insured person's regular route while commuting between home and place of work, or on a trip to assume a job provided for him/her, or a job which is the basis for the insured person's compulsory health insurance; and any injury or disease referred to in the first and second subparagraphs, sustained by the insured person under the circumstances referred to in Article I6 of the CHIA.

Work-related injuries or diseases do not include injuries or diseases caused by (Article 67):

- offensive, negligent or irresponsible behaviour in the workplace or in carrying out the relevant activity, as well as on the insured person's regular route while commuting between home and place of work (e.g. fighting in the workplace or during the break, deliberate infliction of injury to oneself or to another person, performing activities under the influence of alcohol or narcotics, driving under the influence of alcohol or narcotics, etc.).

- activities that are not connected with the performance of work activities (e.g. improper use of break time at work, the use of a break for purposes other than the restoration of physical and psychical abilities necessary to continue the work process, physical activities that are not related to employment, etc.);

- the deliberate infliction of injury by another person, as a result of a personal relationship with the insured person, which is outside the context of the relevant legal work activity;

- chronic disease attacks; and

- congenital or acquired predispositions towards a health condition that may lead to a disease.

An occupational disease is any disease caused by the relatively long influence of the work process and working conditions of a particular job. The list of occupational diseases and activities likely to cause such diseases, as well as identification criteria for occupational diseases are regulated by the Act on the List of Occupational Diseases. 